\title{
Development of Mini Smart Library Direction System Incorporated with the Library of Congress Classification System: A case study of East African Libraries
}

\author{
Adol Dominic Majak Deng ${ }^{1 *}$, Annette Godfrey Mandari ${ }^{2}$, Angelo Bidal Chance Gurisi ${ }^{3}$, and Neema \\ Mosha $^{4}$
}

Research Scholars ${ }^{1-3}$, Head Librarian ${ }^{4}$

School of Computational and Communication Science and Engineering (CoCSE), and NM-AIST Library

The Nelson Mandela African Institution of Science and Technology (NM-AIST), P.O. Box 447

Arusha, Tanzania

\begin{abstract}
This paper focuses on the development and implementation of a Mini Smart Library Direction System that is integrated with the Library of Congress Classification (LCC) System to facilitate easy book tracing in libraries. A library is a storage building with ample information about books, etc., and their various topics. The LCC System is a method of categorizing books into classes. Technology is evolving and libraries today are becoming more digitized. This in turn, helps to facilitate easy access to library bookshelves. Nowadays, many libraries have adopted an electronic system that catalogues books, although the process of searching for a book may vary slightly from one library to another. However, the library user needs to search in the library catalogue to identify the needed book and use the call number to find the book on the shelf. In case the library user fails to locate the book, the librarian assists. This manual method has several drawbacks, including time spent walking around in the library searching for the book, and stress experienced throughout the process. According to case studies conducted at the Nelson Mandela African Institution of Science and Technology in Tanzania, and the University of Juba, South Sudan, it is noted that students are having trouble finding books in libraries. The developed system is based on the Internet of Things, and it connects through Wi-Fi to browse a specific shelf that illuminates based on the user's preferences via a keypad/mobile application (Blynk). It has a web-based user guide manual. The system was tested against the essential characteristics of embedded and IoT systems. As a result, the system is suitable for usage in supermarkets, warehouse stores, and other inventory management applications.
\end{abstract}

Key Words: Digitization, Blynk, IoT, Library of Congress Classification, Smart Library.

\section{INTRODUCTION}

A library is a collection of organized information sources which is made accessible to the people and that the information is usually in a physical or digitized format [1]. Library collection is an essential development process for the accumulation of materials such as books and other materials needed by the users and owned by a library. Such collections may range from tangible paper materials to digitized ones in repositories.

Progresses in science and technology have made it possible for traditional libraries to be turned into digitized smart ones. The process of locating books in the library would be deemed almost impossible without some kind of classification system. However, the classification systems come with some shortcomings, this is true especially for big libraries. For example, looking for a particular class number (subject) has become an issue due to the increased number of book publications especially during this technological era. Therefore, these shortcomings have led to time wastage by library users and suffer the stress incurred during the process of trying to locate books. A survey conducted by [2] on "An Empirical Investigation of Problems and Issues being faced by the students while using Libraries in University of the Punjab, Lahore" suggests that students disagreed that library resources are easy to find. Similar random survey was done in University of Juba, South Sudan in January 2021, and the result also suggests that students waste much time pacing around looking for a particular book's class number using the Library of Congress Classification (LCC) System. 
Many of the current academic library systems around the world use one of the two major library classification systems: Dewey Decimal and Library of Congress Classification.

These library classifications systems can also be referred to as book classification systems. These are tools used in the process of categorizing/sorting which involves organizing, grouping and arranging books and other materials in the library shelves.

The difference between the two library classifications systems is that the Library of Congress Classification (LCC) uses an outline view whereas Dewey uses a hierarchical approach in its organization and the Library of Congress Classification is used by many universities and research institutions whereas the Dewey system is mostly used by public libraries [3].

Zeroing on the Library of Congress Classification (LCC) System as the target in academic institutions such as The Nelson Mandela African Institution of Science and Technology (NM-AIST), University of Juba (UoJ), and many others. The Library of Congress Classification (LCC) System is done in the form of classes. Those classes range from A to Z, for instance General works for class A with subclasses $\mathrm{AC}, \mathrm{AE}, \mathrm{AG}, \mathrm{AI}$ and so forth.

The Mini Smart Library Direction System project aims to incorporate the Library of Congress Classification (LCC) System with a system which will aid in locating a particular shelf pertaining to a book. It is a common phrase that "Time is Money" and everyday people from various industries are coming up with systems and innovations to save up more on time. This system will not only help solve the time wasted and the stress incurred in the search for a particular shelf in the library, but also the pacing back and forth which distracts other library users.

\subsection{Problem Statement}

The Library of Congress Classification (LCC) System is the current widely used library system in the world developed by Herbert Putnam in 1897 for the purpose of organizing and arranging book collections of the Library of Congress [3]. However, the Library of Congress's collections are universal since they include research materials from all parts of the world. It works in classes A to Z and each class is subdivided into a number of sub-classes i.e., classes A to $\mathrm{Z}$ are categorized into General Works for class $\mathrm{A}$, Philosophy, Psychology for class B etc.

Such a manual system poses a number of disadvantages such as: time wastage in shelves locating the classification number in search of a particular book, interfering with reader's concentration due to the pacing around in search of a book's classification number and the stress encountered when searching for the books.

Libraries are intellectual structures with valuable culture and ample access to information and storage of books. Implementing a Mini Smart Library Direction System in big libraries would minimize the issues mentioned i.e., time wasted, etc. and elevate the use of the Library of Congress Classification (LCC) System. However, the Mini Smart Library Direction System is a system with the sole purpose of directing a person to the location of the class numbers of the books in the shelves. The system illuminates the particular pressed classification number (class number) of the book through the help of a database system which consists of all the classification numbers of the Library of Congress Classification (LCC) System. Libraries, like the rest of the world, should not be left behind as the world shifts rapidly from nontechnical to fully technological methods of doing things. Technology has really changed the ways things are done and, therefore, the world is greatly motivated to implement technology in all aspects of life.

\subsection{Objectives}

The main objective of this research is to develop and implement a Mini Smart Library Direction System that is integrated with the Library of Congress Classification (LCC) System to facilitate easy book tracing in libraries.

\section{RELATED WORKS}

\subsection{Existing Systems}

1. Signages provide information or a way of communication, promotion and set the tone of the library environment [4], [5].

2. Library Classification Systems e.g., Library of Congress and Dewey etc.

3. Digital signages that consist of nothing more than a display device connected to a non-networked computer, the signage content of which is loaded manually via discs or flash-memory devices [8].

4. Systems that monitor books in a library using RFID technology, they only facilitate the issuing and returning of books in a library [9].

5. The robotic system that uses a LAN network which delivers books anywhere on a campus and takes books back to a library [10]. 
According to the Statement on Libraries and Development made by the International Federation of Library Associations and Institutions [6], the library is the only place in many communities where people can access information that will help improve their education, develop new skills, find jobs, build businesses, make informed agricultural and health decisions or learn about environmental issues.

For a library to be useful to everyone, directions to its resources have to be provided through friendly and easily understood signage. Signage represents more than directions or policies; it is informational, promotional, and sets the tone of the environment. To be effective, signage must be consistent, concise, and free of jargon and punitive language [7]. Sometimes signage provided in a library can be hard to understand or even misleading. The signage audit revealed a plethora of signs containing outdated, longwinded messages, inconsistent design, and confusing, contradictory, and sometimes punitive language [7].

As the world is being fully digitalized, there is a need to digitalize the barn of knowledge too. New technologies, such as the Internet of Things (IoT), have brought both opportunities to upgrade library infrastructure and the challenges of adapting to rapid technical development. However, there are still some challenges in fully making use of the new technologies. Some people think this new technology can only be used as a standalone system. In its simplest form, digital signage may consist of nothing more than a display device connected to a non-networked computer, the signage content of which is loaded manually via discs or flashmemory devices [8].

Though today there is a system to monitor books in a library, a major difficulty in the present library system is that RFID technology finds its application only in the issuing and returning part of the library system [9]. There is a paper which emphasizes how a robot can issue and return a book in the library. The robotic system includes a robot that uses a LAN network with static IP for accessing the robot from anywhere on the campus [10]. Besides, there is also use of Radio Frequency Identification (RFID) and Wireless Sensor Network (WSN) technologies that enables connectivity of books or other text typologies with real-time communication and monitoring as well as tracking of labeled objects (books) [11]. This is a very good technology, however it cannot be afforded by all levels of libraries and it is expensive to implement.

The existing library system does not provide direction to the users. The present system does not provide any assistance to the user to track the book right to its rack [8]. The findings from the literature provided a framework for establishing the need and the importance for coming up with a new system.

\subsection{Proposed System}

The proposed Mini Smart Library Direction System incorporated with the Library of Congress Classification (LCC) System is to fill the gap identified through the literature review. After carefully reading and understanding the existing literature, it becomes clear that the existing systems do not exactly provide what the proposed system will provide.

The system is to provide digital directions to the library users remotely. It is important to have an attractive and effective sign system that is consistent throughout all public areas of the library. Using embedded systems to digitalize the library will be of great importance. Digital information storage technology and information communication technology together can revolutionize the concept of the library system and can transform it into a digital library [12], [13]. If accepted, this system will replace the physical signage in libraries, will create space and keep libraries clean. Thus, the system will not only provide real time information to the users, but also the information it gives will be specific to the user's need and as a result, it reduces time wasting in a library.

\subsection{Advantages of the proposed System}

The System will provide a better alternative to physical signages in the library, which will create space and keep a library clean, the system will provide real time information to users, the information it gives will be specific to the user's need and as a result, it reduces time wasting in a library.

\section{DEVELOPMENT METHODOLOGY}

\subsection{Case study}

The Nelson Mandela African Institution of Science and Technology (NM-AIST) in Tanzania and University of Juba (UoJ) in South Sudan. Data collection methods

\subsubsection{Primary data collection method}

The primary data for this project were taken from The Nelson Mandela African Institution of Science and Technology (NMAIST) library and University of Juba (UoJ) library. At the Nelson Mandela African Institution of Science and Technology, the users of the library were closely observed with the aim of understanding their feelings, especially the new students. At the 
University of Juba fifty (50) students were randomly asked about their experiences in the library as they tried to get a book. The statement is, 'It is easy to get a particular book in the library', and 58\% of the respondents said that getting a particular book from the library using the Library of Congress is a stressful experience. Below is the table showing the results.

Table 3.1. Results obtained from University of Juba

\begin{tabular}{|l|c|c|}
\hline \multicolumn{1}{|c|}{ Degree } & Frequency & Percentage \\
\hline SA & 3 & $6 \%$ \\
\hline A & 5 & $10 \%$ \\
\hline $\mathrm{N}$ & 8 & $16 \%$ \\
\hline $\mathrm{D}$ & 29 & $58 \%$ \\
\hline SD & 5 & $10 \%$ \\
\hline Total & $\mathbf{5 0}$ & $\mathbf{1 0 0 \%}$ \\
\hline
\end{tabular}

Key:

SA: Strongly Agree

A: Agree

N: Neutral

D: Disagree

SD: Strongly Disagree

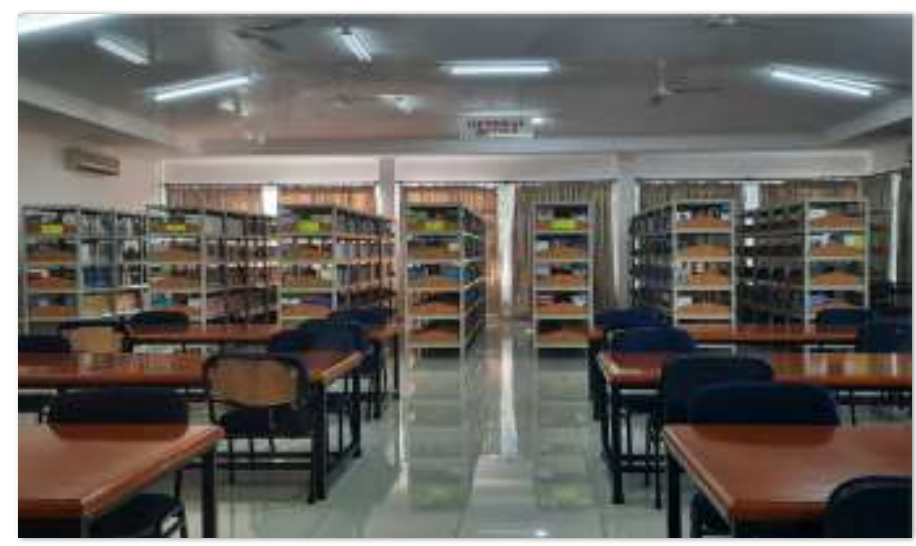

Picture 3.1: Showing The Nelson Mandela African Institution of Science and Technology (NM-AIST) Library in Tanzania

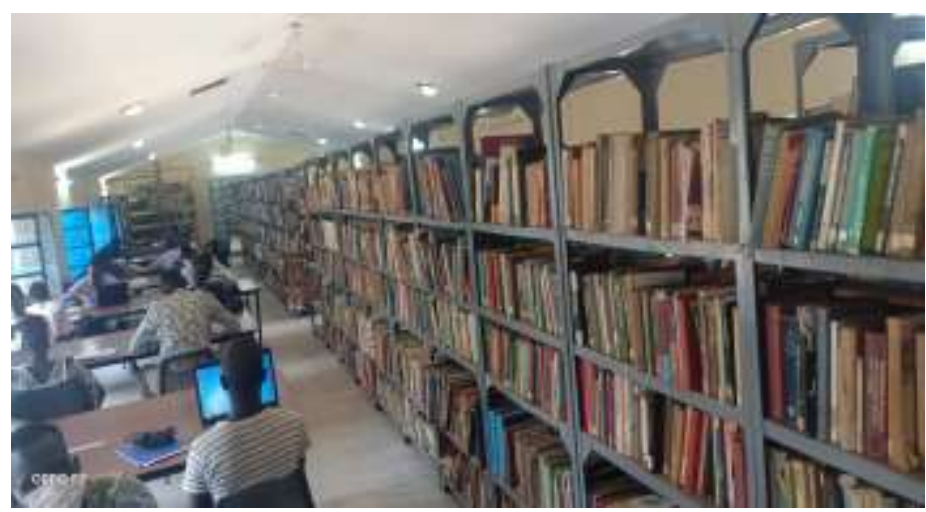

Picture 3.2: Showing University of Juba (UoJ) Library in South Sudan

\subsubsection{Secondary data collection method}

In this part, the findings were mostly from the books, journals, and internet resources that address the subject. 


\subsubsection{Data analysis}

The data were entered in the table, therefore, there was no need to use any special software for analysing the data.

\subsection{System Requirements}

Any usable system requires both software and hardware for its operation and the Mini Smart Library Direction System incorporated with the Library of Congress Classification (LCC) System as well as the Web-based system is not an exception.

\subsubsection{Software requirement}

Software plays an important part in a system as it provides the system with the instructions for its operations. For this particular system, the main languages and software used are; Hyper Text Markup Language (HTML), Cascading Style Sheets (CSS), Java Script, Hypertext Preprocessor (PHP), MySQL/SQL, Arduino IDE, EasyEDA and Blynk application. For the system to perform its required function, a Web-based system is an integral as a user guide.

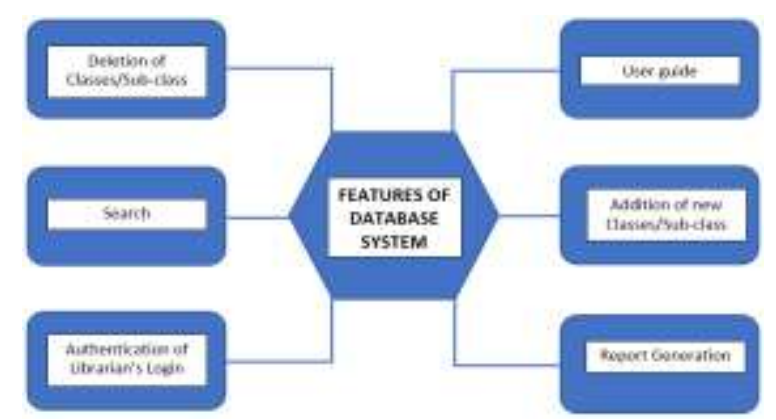

Figure 3.1: MSLDS Web-based System Block Diagram

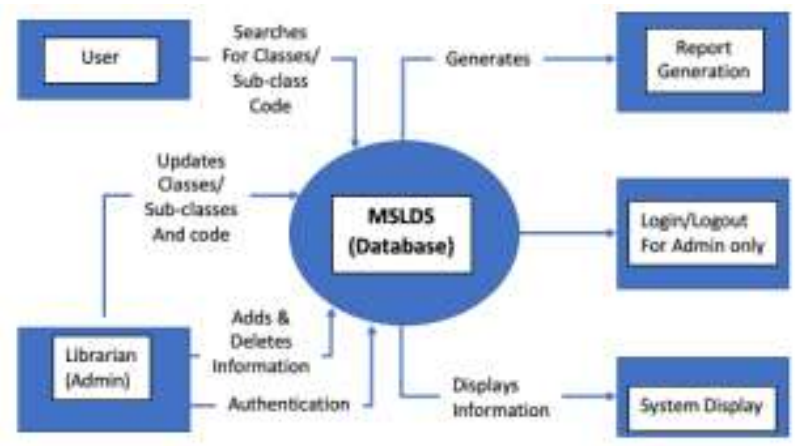

Figure 3.2: Context Diagram

\subsubsection{Hardware requirement}

Without physical structure, it is impossible to have a system such as Mini Smart Library Direction System. Therefore, below are the structural parts required for the operation of the proposed system.

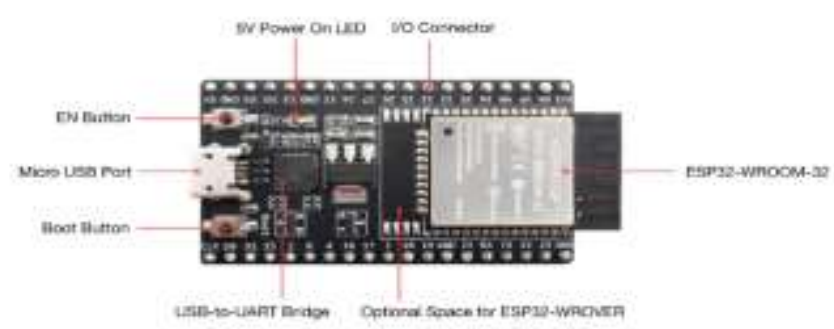

Figure 3.3: ESP32 Microcontroller [14] 
International Journal of Advances in Scientific Research and Engineering (ijasre), Vol 7 (10), October -2021

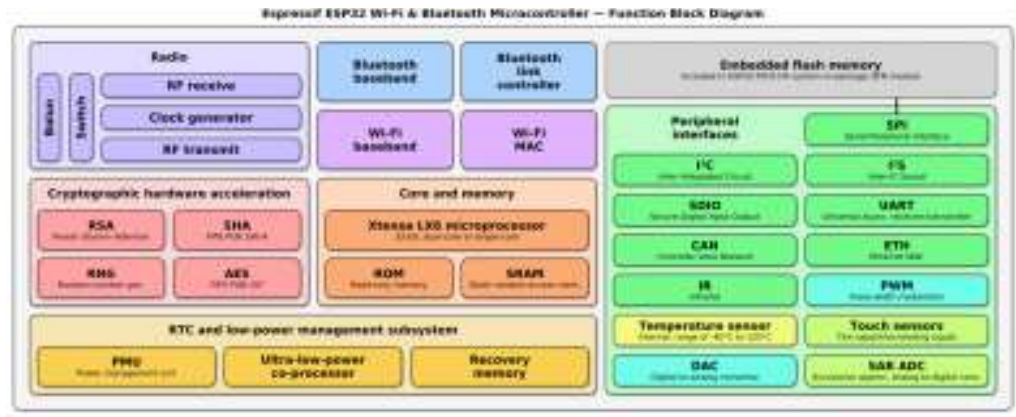

Figure 3.4: In built functional parts of ESP32 [15].

Table 3.2: Other Hardware components

\begin{tabular}{|c|c|}
\hline S. No. & Components \\
\hline 1 & 8 channels relays \\
\hline 2 & $20 x 4$ LCDs \\
\hline 3 & Push buttons \\
\hline 4 & 5 V power source \\
\hline 5 & Jumpers \\
\hline 6 & Buzzer \\
\hline 7 & $5 \mathrm{~V}$ Fan \\
\hline 8 & Resistors \\
\hline 9 & Male AC power socket \\
\hline 10 & Cable connectors \\
\hline 11 & ESP32 \\
\hline 12 & I2C module \\
\hline
\end{tabular}

\subsection{System Development}

In the development of the Mini Smart Library Direction System incorporated with the Library of Congress Classification (LCC) System, agile is used because of its flexibility and adaptability.

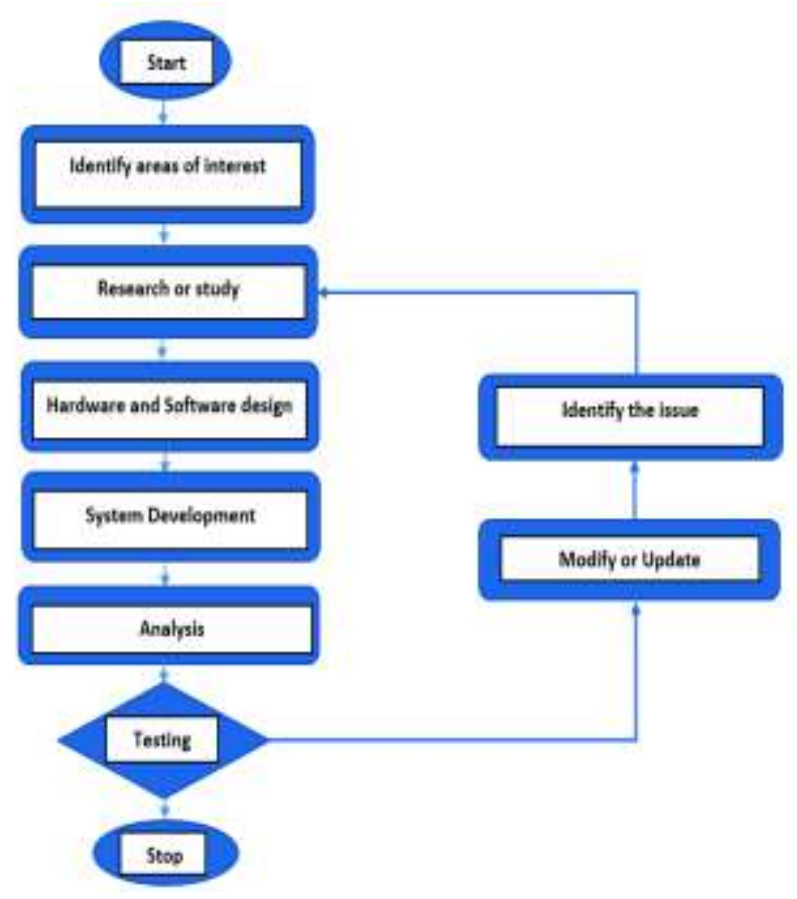

Figure 3.5: System flowchart 


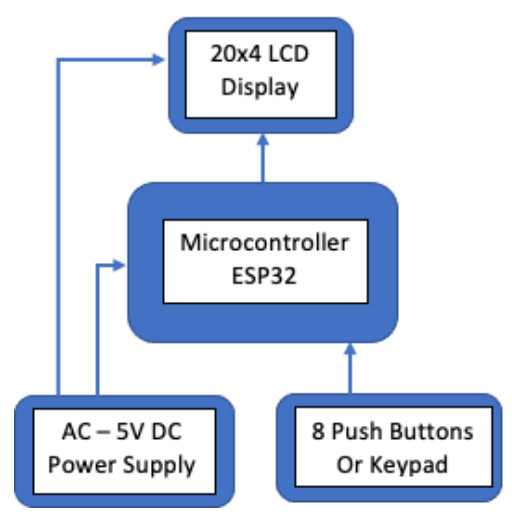

Figure 3.6: Master System Block Diagram

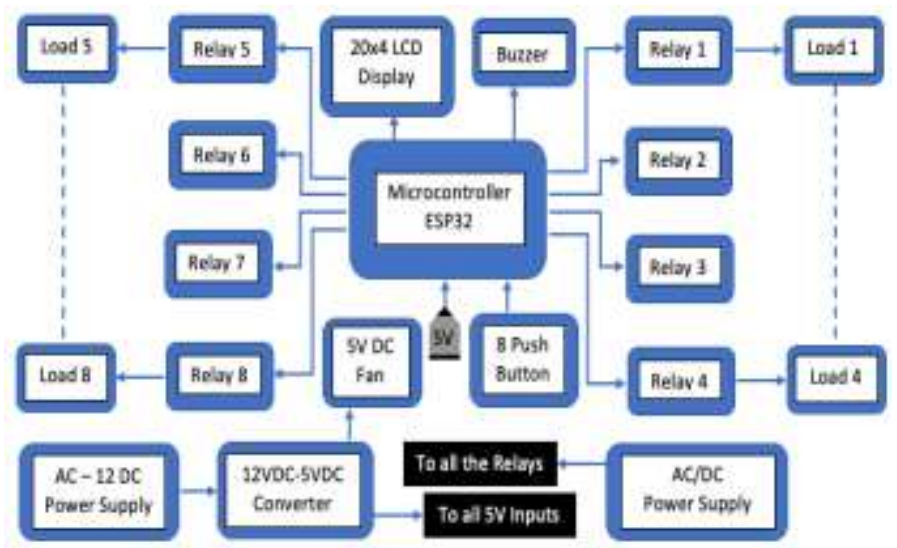

Figure 3.7: Slave System Block Diagram

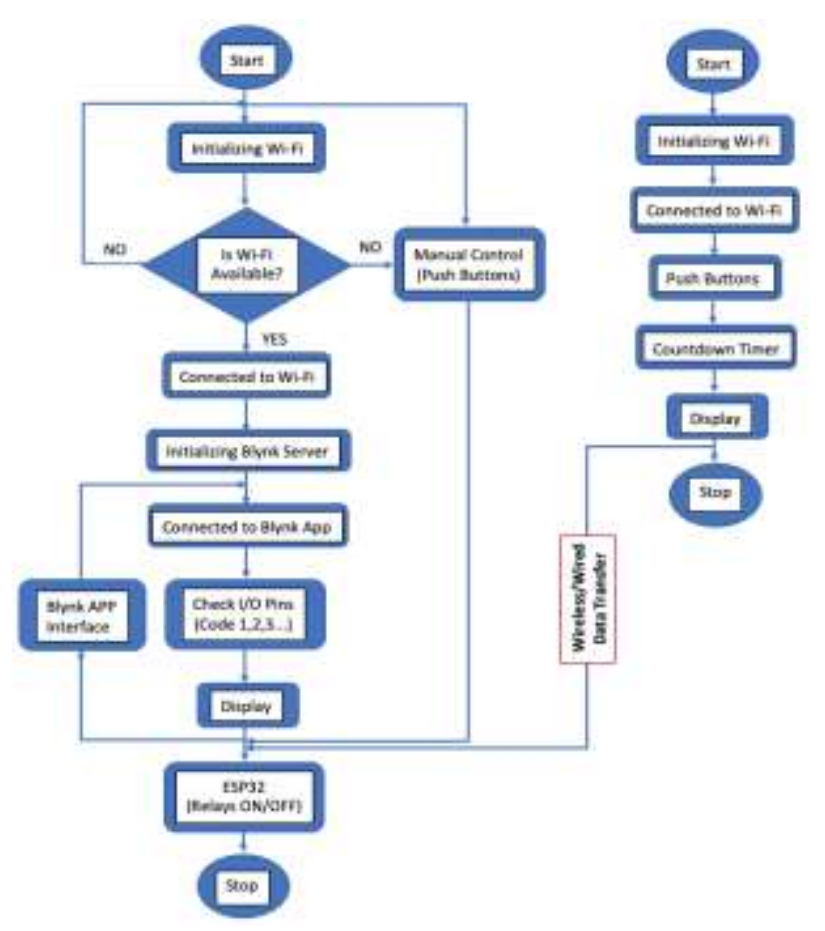

Figure 3.8: Master and Slave Flowchart 
International Journal of Advances in Scientific Research and Engineering (ijasre), Vol 7 (10), October -2021

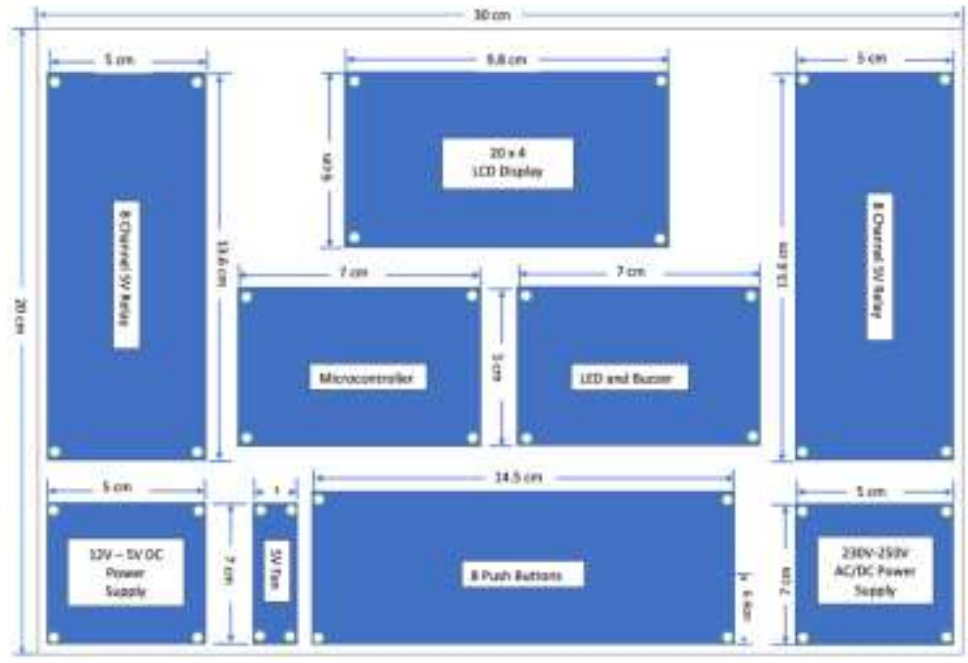

Figure 3.9: Mechanical Drawing

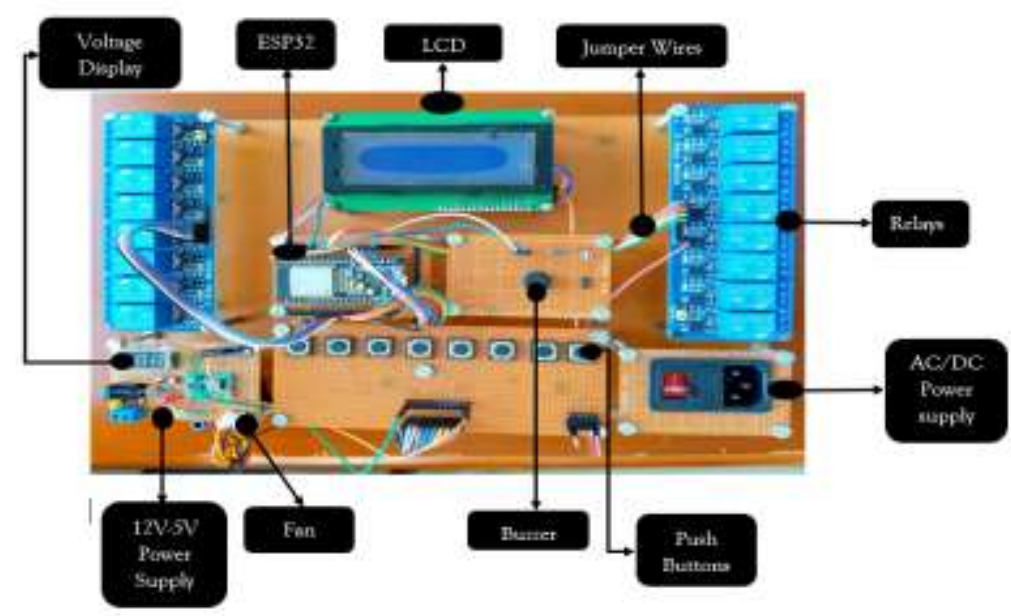

Figure 3.11: Complete hardware
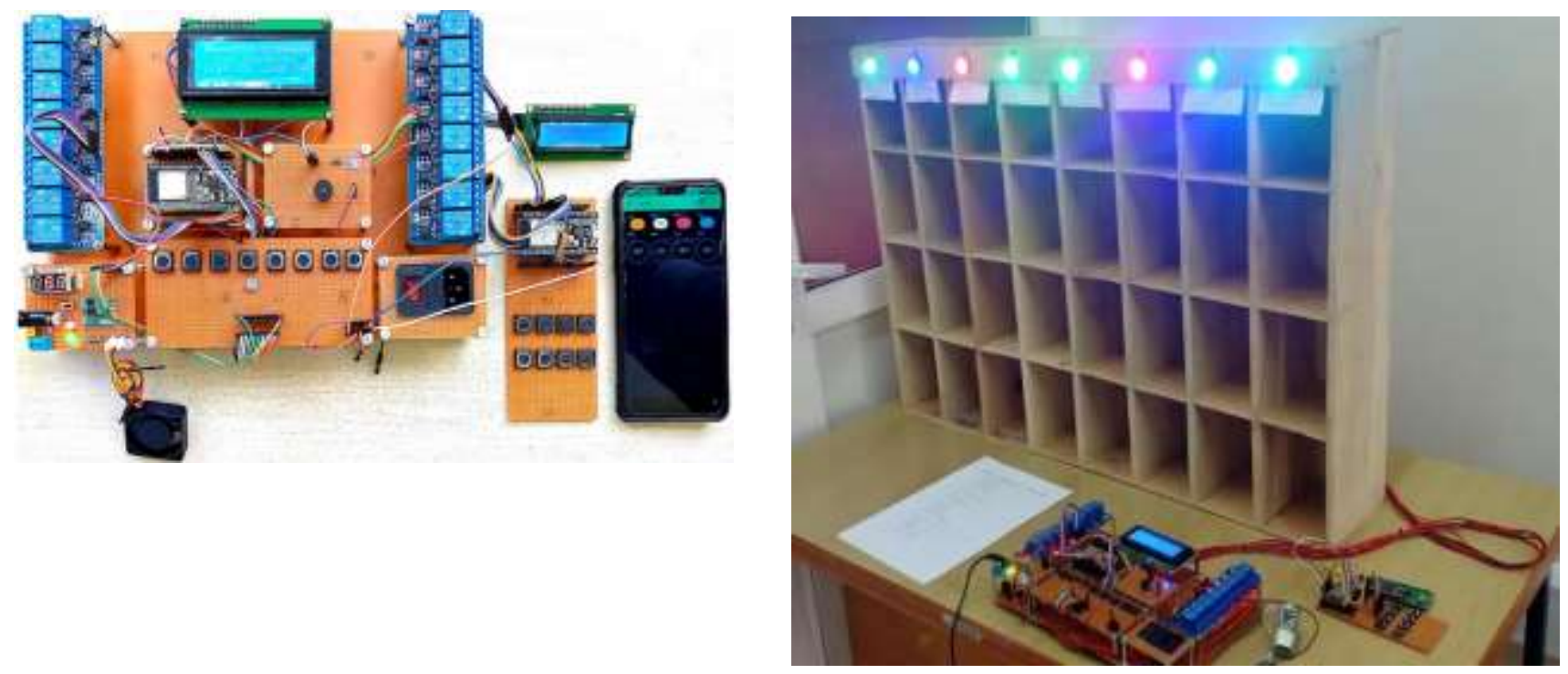

Figure 3.12: System at the testing stage 


\section{EXPERIMENTS AND RESULTS}

The System was tested against all the basic characteristics of embedded and internet of things criteria, and found desirable.

Firstly, the system was tested to check against overheating based on the intervals of one hour, three hours, eight hours, twelve hours and lastly twenty-four hours. All the tests showed no overheating in the system. Secondly, it was tested against its specific task of getting connected to the Wi-Fi, accepting inputs from smartphones, or the push buttons and outputting the desired result for which it was developed.

The system responds in real-time to its specific function. As soon as the instruction is sent, the system responds immediately. The system has very minimal users interfering with its operation. The minimal interference only results when two or more users are using the system, and one of the users decides to switch off the button which is on off just to cause confusion.

The system is efficient because of its ability to respond in real-time which greatly reduces time wastage and stress. The system is capable of helping the user to do much within the shortest possible time. The system is very reliable. Its performance is not affected by time. Once the system is switched on and connected to the Wi-Fi, it remains stable in its operation without going off or getting disconnected from the Wi-Fi till it is turned off manually.

Furthermore, the system is energy efficient. It can be powered through USB cable from a laptop; therefore, the cost for both running and maintaining the system is very low.

\subsection{Discussion}

Only here is the outcome of the developed system in line with the aims detailed in full. The objectives were met in a simple, practical, and cost-effective manner to improve access to books in libraries.

\subsubsection{The major finding of the study}

Through the studies carried out both at the Nelson Mandela African Institution of Science and Technology in Arusha, Tanzania and University of Juba in Juba, South Sudan. It is clear that students are finding it hard in the libraries when trying to locate a particular book.

\subsubsection{The meaning of the findings}

Based on the findings, it is clear that there is a need to ease the process of locating a book in a library without much stress of going through several shelves in a library. As the results of the findings, the proposed system is being developed to cover the gap in the current library systems.

\subsubsection{Significance of the study}

Many systems have been developed and still more are being developed to facilitate and ease the use of libraries and this research is only to add to the other existing systems. A survey conducted by [2] on "An Empirical Investigation of Problems and Issues being faced by the students while using Libraries in University of the Punjab, Lahore" suggests that students disagreed that library resources are easy to find. Therefore, to ease the access to library resources, Mini Smart Library Direction System incorporated with the Library of Congress Classification (LCC) System should be a part of the much-needed improvement.

Therefore, as mentioned earlier, the system will help solve the time wasted and the stress incurred in searching for the books in the libraries, not only that but also the pacing forth and back which distracts other library users.

\subsection{The system operation}

The Mini Smart Library Direction System's operation is based on the Library of Congress Classification (LCC) System. The system has a database for storing all the Library of Congress Classification (LCC) System list; a number of classes and subclasses of the same category are listed on the database which is linked to a web to represent a particular shelf according to the particular library design of using Library of Congress Classification (LCC) System. A user can check or search for a particular book using class description (subject name) from a web designed as a user guide in order to get the code (ID) representing that specific shelf where the book is located. Once the user gets the code, the code can be keyed in using a smartphone or the buttons and the light on the shelf illuminates with a real-time update on the application. 


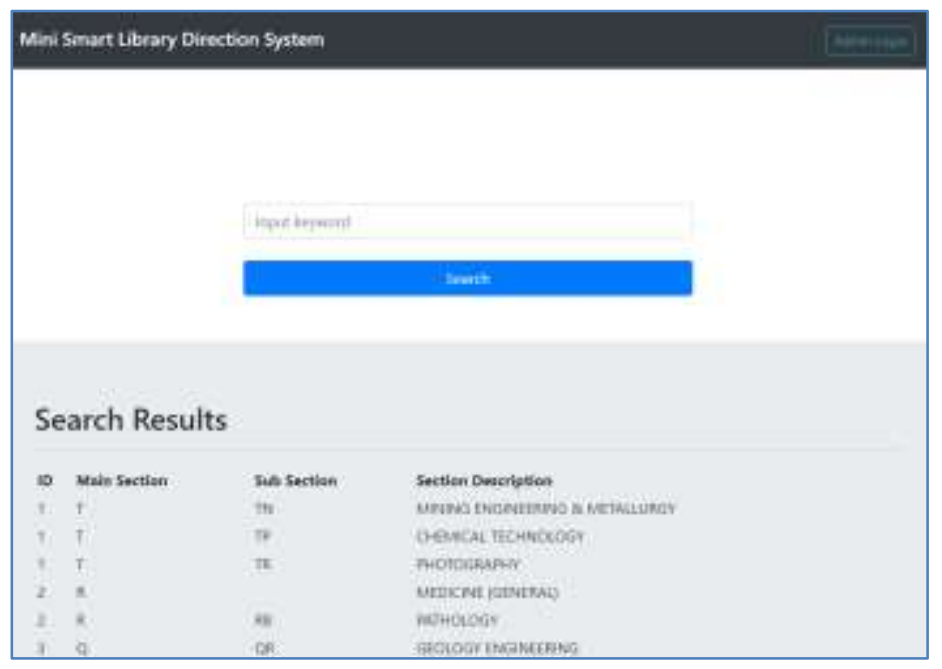

Figure 3.13: Web-based System as a user guide

The hardware system operates in two independent modes which are wireless and wired. Wireless mode is based on the use of WiFi. The system has to be connected to Wi-Fi for operation on smartphones which have Blynk applications. Wired operation mode is designed for the use by those who do not have mobile phones, or when Wi-Fi is down. This operation is physically based on pushing buttons.

The hardware system also has master and slave systems. The master on this system controls the activities of the slave, which are push buttons as a keypad.

\subsection{Scope of the study}

This study aims at the Library of Congress Classification as its basic building block for the provision of an IoT technology-based system for easy access to books in academic institutions' libraries. The Library of Congress Classification (LCC) System is based on classes. The classes range from A to Z, for instance General Works for class A, and the class has sub classes AC, AE, AG, AI and so forth on which the Mini Library Direction System is going to base its operation.

\subsection{Limitations of the study}

This project is only designed to operate on the existing Library of Congress Classification (LCC) System. However, it can still be upgraded to use multiple classification systems. The survey for this project has not been taken widely due to time and other resources limitations.

The system is not designed to target an individual book in a shelf, but rather a whole shelf containing books with the same topic, for instance, History of Asia.

The system is internet dependent. Meaning it requires the internet for its operation in real-time when using a Blynk Application on a smartphone.

\section{CONCLUSION AND FUTURE WORKS}

Technology is ever expanding and this in turn leads to further enhancements of every day's human activities. The prototype shows how to access books in a library by the use of technology. Mini Smart Library Direction System is designed to facilitate easy access to the books in a library. Since Mini Smart Library Direction System provides easy access to the books in a library, it is simple, user friendly and cost effective locally made to meet user needs.

After testing Mini Smart Library Direction System, it is concluded that it will greatly improve users' access to the books in a library, therefore, it is recommended for the use in a library. The system can also be used for directing customers in a supermarket to specify aisles and item's location. The same system can also be used for directing travelers to specific entry and exit gates at an airport. More effective techniques to increase the keypad's function to a real-time update on the user side are needed to achieve greater functionality, similar to when using the App on a smartphone. Another function to be added to the system's scope is the incorporation of an RFID system to regulate the misplacement of books in the shelves. 


\section{ACKNOWLEDGMENT}

First and foremost, we give thanks to the Almighty God for his grace and abundant blessings from the time we start our project to its successful final stage.

Secondly, we would like to thank our supervisor: Dr. Neema Mosha for her supervision, support and mentorship from the start of the project to the end.

Thirdly, we would like to thank and express our deepest gratitude to The Nelson Mandela African Institute of Science and Technology (NM-AIST) and School of Computational and Communication Science and Engineering (CoCSE) for allowing us to use their facilities such as the labs which helped facilitate our project work.

Fourthly, we would like to thank our sponsor The Center of Excellence for ICT in East Africa (CENIT@EA).

Fifthly, we are extremely thankful and grateful to our friends and families for their encouragement and support in various ways.

Lastly, We express our heartfelt gratitude to our friends and families for their encouragement and support. And not forgetting ourselves for pushing each other and forming a workable team that aims at the stars.

\section{REFERENCES}

[1] A. Tosin, T. Library Management System By Being a Project Report Submitted To the Department of Computer Science , Faculty of Science, Federal University Oye Ekiti, Ekiti State, Nigeria in Partial Fulfilment of the Requirement for the Award of Bachelor of Science, 2015 (. 70) https://www.academia.edu/33632232/LIBRARY_MANAGEMENT_SYSTEM

[2] Q. Ch. An Empirical Investigation of Problems and Issues Being Faced by the Students While Using the Libraries in University of the Punjab, Lahore. Bulletin of Education and Research, 2017 (39(2), 225-238).

[3] M. L. Chan, S. S. Intner, \& J. Weihs, Guide to the Library of Congress classification. ABC-CLIO. 2016.

[4] F. A. Stempler, \& A. M. Polger. Do You See the Signs? Evaluating Language, Branding, and Design in a Library Signage Audit. 2013. Public Services Quarterly, 9(2), 121-135. https://doi.org/10.1080/15228959.2013.785881

[5] A. M. Polger, \& F. A. Stempler. Out with the Old, in with the New: Best Practices for Replacing Library Signage. Public Services Quarterly, 2014. 10(2), 67-95. https://doi.org/10.1080/15228959.2014.904210 Reference Services Review, 41(3), 503-513. https://doi.org/10.1108/RSR-02-2013-0006

[6] IFLA. IFLA Statement on Libraries and Development.https://www.ifla.org/publications/ifla-statement-on-libraries-anddevelopment. Accessed August 2013.

[7] F. A. Stempler. Navigating circular library stacks: A case study on signage. 2013.

[8] College \& Research and Library News. Signs of Success: Digital signage in the library.https://crln.acrl.org/index.php/crlnews/rt/printerFriendly/8387/8562. Accessed 2010 (Vol 71. No 6).

[9] A. L. A. Brian, L. Arockiam, \& K. S. D. P. Malarchelvi. An IOT based secured smart library system with NFC based book tracking. International Journal of Emerging Technology in Computer Science \& Electronics (IJETCSE), 2014 (11(5), 18-21).

[10] T. Gupta, R. Tripathi, K. M. Shukla, \& S. Mishra. Design and Development of IOT Based Smart Library using Line Follower Robot. International Journal on Emerging Technologies, 2020 (11(2), 1105- 1109)

[11] M. Bayani, A. Segura, M. Alvarado, \& M. Loaiza. IoT-based library automation and monitoring system: developing an implementation framework of implementation. E-Ciencias de la Información. 2018 Jun;8(1):83-100. https://doi.org/10.15517/eci.v8i1.30010

[12] S. P. Aithal. (2016). Smart Library Models for Future Generations. International Journal of Engineering Research and Modern Education (IJERME) ISSN (Online, I(I), 2016 (2455-4200).

[13] S. Gul, \& S. Bano. Smart libraries: an emerging and innovative technological habitat of 21st century. Electronic Library, 2019. 37(5), 764-783. https://doi.org/10.1108/EL- 02-2019-0052

[14] Arup. IoT Workshop 2020. Github. Arup-groug. 2 Nov 2020. Retrieved from: https://github.com/arupgroup/iot_workshop_2020 
[15] B. Krent. Function block diagram for Espressif's ESP32 series of Wi-Fi/Bluetooth chips. Wikimedia Commons. Accessed 3 September 2018. https://commons.wikimedia.org/wiki/File:Espressif_ESP32_Chip_Function_Block_Diagram.svg

\section{AUTHORS BIOGRAPHS}

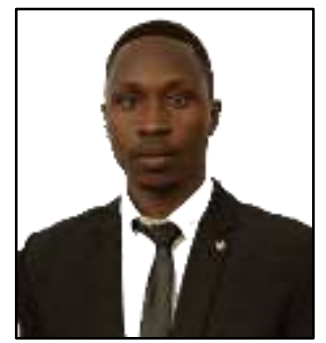

Adol Dominic Majak Deng obtained his Bachelor of Science in Electrical and Electronics Engineering (Honours) from Manipal International University (MIU), Malaysia in June 2017. Currently pursuing Master's in Embedded and Mobile Systems (EMoS) program at The Nelson Mandela African Institution of Science and Technology (NM-AIST) in Tanzania, with specialization in Embedded Systems. Worked as an Assistant Director in Electrical and Electronics at the directorate of Engineering and Construction Management, University of Juba (UoJ) and a teaching Assistant volunteer. His research interests and drive lie in systems automation, control systems, Embedded Systems and Energy. Email: denga@nm-aist.ac.tz

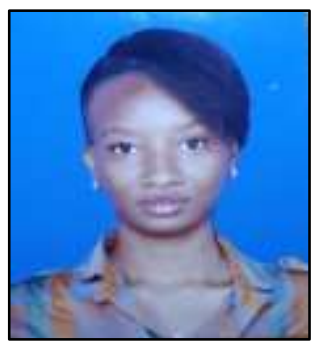

Annette Godfrey Mandari obtained her Bachelor of Science in Electronics and Communication Engineering (ECE) from St. Joseph University in Tanzania. Currently, she is taking her Master's in Embedded and Mobile Systems (EMoS) program at The Nelson Mandela African Institution of Science and Technology (NM-AIST) in Tanzania. Her drive and interests lie in solving society problems using her knowledge and skills attained throughout her career in the health, ICT and automation sector. Email: mandaria@nm-aist.ac.tz

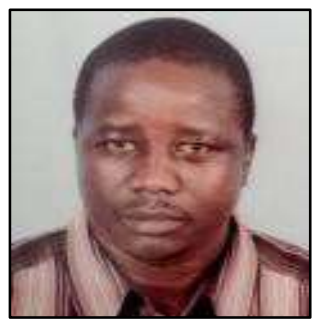

Angelo Bidal Chance Gurisi obtained Ordinary and Advanced Diplomas in Information Communication Technology Systems and Telecommunication Engineering from Graffins College, Kenya, Bachelor of Science in Business Information Technology from Limkokwing University of Creative Technology, Malaysia, Master of Arts in Peace and Development Studies from University of Juba, South Sudan. He is currently perusing Master of Science in Embedded and Mobile Systems at The Nelson Mandela African Institution of Science and Technology. His main interests are in using ICT for conserving wildlife, addressing security issues and improving construction processes. Email: gurisia@nm-aist.ac.tz

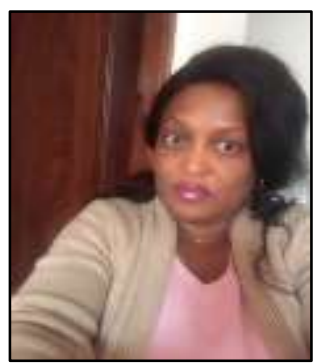

Dr. Neema Mosha is the Head of Library Services at the Nelson Mandela African Institution of Science and Technology (NM-AIST), located in Arusha, Tanzania. Neema has a PhD in Information Science (Knowledge Management and Web 2.0 tools) from the University of South Africa (UNISA), Pretoria, South Africa, Master of Information Technology (M.IT) from the University of Pretoria (UP), Pretoria, South Africa, Master of Information Studies from the University of Dar-es-Salaam (UDSM), Dar-esSalaam, Tanzania and a Bachelor Degree of Education (Hons.) from the Open University of Tanzania (OUT). Her research focuses on Research Data Management (RDM), Data Management Plan (DMP), Data Repositories (DR) management, knowledge and information management and sharing. She engaged in various community outreaches to enable communities to use Telecenters for their information needs to cope with their daily activities. Dr. Neema has published widely in peer- reviewed journals and book chapters. She has also presented papers in many international and local conferences within and outside the country. She serves as an external examiner for UNISA, NM-AIST, and Moshi Co-operative University (MoCU). She participated in CODATA online course facilitated by the University of Pretoria (UP), South Africa to enable Universities working with research data. Email: neema.mosha@nmaist.ac.tz 